Jahangirnagar University J. Biol. Sci. 8(1): 1-7, 2019 (June)

\title{
Effect of Ashwagandharista (Withania somnifera) on the kidney functions of male and female rats
}

\author{
Tasmina Rahman*, Md. Rakib Hasan and M. S. K. Choudhuri \\ Department of Pharmacy, Jahangirnagar University, Savar, Dhaka-1342, Bangladesh
}

\begin{abstract}
The key objective of this present study was to analyze the effect(s) of Ashwagandharishta on the kidney functions of both male and female Albino rats. Chronic toxicity tests were also done. Following treatments the rats were observed for 51 days to know the effects of Ashwagandharishta on kidney functions considering 3 parameters such as serum urea, creatinine and uric acid. Our results failed to exhibit a significant increase in serum urea level at low dose $(\mathrm{P}<0.01)$, medium dose $(\mathrm{P}<0.05)$ and at high dose $(\mathrm{P}<0.001)$ in male rat groups; but with female rat groups our results showed significant increase in serum urea level at three dose levels. Regarding serum creatinine level male rats and female rats showed a trend of increase in level at different dose but effects were insignificant except medium dose in male rats $(\mathrm{P}<0.05)$ Regarding serum uric acid level our results failed to show a significant increase irrespective of dose.
\end{abstract}

Key words: Ashwagandharishta, kidney functions, rats

\section{INTRODUTION}

Analysis of blood and urine samples is essential for the evaluation of kidney (renal) function. The basic renal function tests involve determination of Blood urea nitrogen (BUN), Creatinine, and Creatinine clearance rate. Blood urea nitrogen (BUN) provides a tentative measurement of the glomerular filtration rate, the rate at which blood is filtered in the kidneys. Thus urea is formed in the liver as an end product of protein metabolism and is carried to the kidneys for excretion. Nearly all kidney diseases cause inadequate excretion of urea, elevating urinary nitrogen (UN) level in the blood. Other causes of high UN levels in blood include gastrointestinal bleeding and steroid treatment. Creatinine on the other hand is a breakdown product of creatine, an important component of muscle. The production of creatinine depends on muscle mass. Creatinine is excreted exclusively by the kidneys, and its level in the blood is proportional to the glomerular filtration rate. The serum creatinine level provides a more sensitive test for kidney function than BUN (Margolis, 2012).

Uric acid is a break down product of purines which is normally produced in the body. Most uric acid dissolves in blood and travels to the kidneys and passes out along with urine. If ones body produces too much uric acid or does not remove enough of it, he/she may get sick. A high level of uric acid may cause gout or kidney disease as it forms crystals and kidney stones (Edwards, 2016; Sharfuddin et al., 2016). Therefore, regulation of uric acid production and excretion is essential to maintain a good health. This test was

\footnotetext{
* Corresponding author. Email: tamirahman@yahoo.com
} 
done to see if someone has a high level of uric acid in his/her blood. According to the World Health Organization (WHO), about 80 percent population of the world presently uses herbal medicines for some aspect of primary health care. There is a new interest in traditional medicines because of lower incidence of side effects (Sandhu et al., 2010). Ashwagandharishta is a classical ayurvedic formulation which is used in the treatment of Murchha (syncope) and Mandagni (poor digestive power). It is reported that Ashwagandha (Withania somnifera D.), the key component of Ashwagandharishta (Table 1), (Anonymous, 1992), has got anti-stress and anxiolytic activities because it has brainderived neurotrophic factor (BDNF) that boosts synaptic plasticity, delivers neuroprotection, augments neurotransmission, and produces antidepressant effects (Tanna et al., 2012). Besides it gives anti-ageing, immune-modulatory, cardiovascular protection and hypothyroidism actions as well (Kushwaha \& Karanjekar, 2011). Thus Withania somnifera, has been recognized as an important herb in the Ayurvedic and indigenous medical systems. The roots of this plant is categorised as Rasayanas which promote health and longevity by arresting the ageing process and revitalizing the body in debilitated conditions. Thus it is used as a general tonic as well. Some studies suggest that, it may promote growth in children and improve hemoglobin level by increasing red blood cell count in adults and (Sandhu, et al., 2010) increases heart weight and glycogen in myocardium and liver representing intensification of the anabolic process (Kushwaha et al., 2012). This study was therefore undertaken to evaluate the effects of Ashwagandharista on kidney function in rats of both sexes.

\section{MATERIALS AND METHODS}

Drugs, chemicals and reagents: For the toxicological study, Ashwagandharishta was collected from Sri Kundeswari Aushadhalaya Limited, Chittagong. Ketamine injection was obtained from ACI Pharmaceuticals Limited, Bangladesh. All other reagents, assay kits and chemicals used in this research work were obtained from Human $\mathrm{GmbH}$, Wiesbaden, Germany.

Ingredients: Ashwagandharista was used in a liquid dosage form and the form was prepared using the formula as shown in Table 1.

Experimental Animals: Albino rats (Rattus novergicus : Sprague-Dawley strain, 48 weeks old, 70-80 g) of both sexes bred and maintained at the animal house of the Department of Pharmacy, Jahangirnagar University, were used for toxicological experiment. The rats were kept in a animal house meeting the standard conditions. The rats were fed with rat chow prepared according to the formula developed by Bangladesh Council of Scientific and Industrial Research (BCSIR) and water was given ad libitum. The rats were maintained at 12/12 hour day- night cycle. The study was carried out in absolute compliance with the ethical guide for care and use of laboratory animals approved by Biosafety, Biosecurity and Ethical Committee of Faculty of Biological Sciences, Jahangirnagar University. 
Table 1. Botanical name of ingredients along with the amount used to prepare Ashwagandharista (ASG)

\begin{tabular}{|c|c|c|}
\hline Sanskrit Name & Botanical Name & Amount of ingredient \\
\hline Ashwagandha & Withania somnifera & $2.400 \mathrm{~kg}$ \\
\hline Sweta Musli & Asparagus adscendens & $960 \mathrm{~g}$ \\
\hline Manjishtha & Rubia cordifolia & $480 \mathrm{~g}$ \\
\hline Hareetaki & Terminalia chebula & $480 \mathrm{~g}$ \\
\hline Haridra & Curcuma longa & $480 \mathrm{~g}$ \\
\hline Daruharidra & Berberis aristata & $480 \mathrm{~g}$ \\
\hline Yashtimadhu & Glycyrrhiza glabra & $480 \mathrm{~g}$ \\
\hline Rasna & Pluchea lanceolata & $480 \mathrm{~g}$ \\
\hline Vidarikanda & Pueraria tuberose & $480 \mathrm{~g}$ \\
\hline Arjun Tvak & Terminalia arjuna & $480 \mathrm{~g}$ \\
\hline Mustaka & Cyperus rotundus & $480 \mathrm{~g}$ \\
\hline Trivrit & Ipomoea turpethum & $480 \mathrm{~g}$ \\
\hline Anantamool & Hemidesmus indicus & $384 \mathrm{~g}$ \\
\hline Krishna Sariva & Cryptolepis buchanan & $384 \mathrm{~g}$ \\
\hline Rakta Chandan & Pterocarpus santalinus & $384 \mathrm{~g}$ \\
\hline Chandan & Santalum album & $384 \mathrm{~g}$ \\
\hline Vacha & Acorus calamu & $384 \mathrm{~g}$ \\
\hline Chitrak Mool & Plumbago zeylanica & $384 \mathrm{~g}$ \\
\hline Water for decoction & $98.304 \mathrm{~L}$ reduced to & $12.288 \mathrm{~L}$ \\
\hline Dhataki puspa & Woodfordia fruticosa & $768 \mathrm{~g}$ \\
\hline Madhu & Honey & $14.400 \mathrm{~kg}$ \\
\hline Shunthi & Zingiber officinale & $96 \mathrm{~g}$ \\
\hline Maricha & Piper nigrum & $96 \mathrm{~g}$ \\
\hline Pippali & Piper longum & $96 \mathrm{~g}$ \\
\hline Tvak & Cinnamomum zeylanicum & $192 \mathrm{~g}$. \\
\hline Tejpata & Cinnamomum tamala & $192 \mathrm{~g}$. \\
\hline Elach & Elettaria cardamomum & $192 \mathrm{~g}$. \\
\hline Priyangu & Callicarpa macrophylla & $192 \mathrm{~g}$. \\
\hline Nagakeshar & Mesua ferrae & $96 \mathrm{~g}$. \\
\hline
\end{tabular}

\section{Experimental design}

Acute toxicity study: An acute oral toxicity test was performed following the guidelines of OECD, 2000. Sixteen male \& female rats (each averages 70-80 g body weight) were selected and divided into four groups, each group consists of four animals and 4 different doses $(1000 \mathrm{mg} / \mathrm{Kg}$ of body weight, $2000 \mathrm{mg} / \mathrm{Kg}, 3000 \mathrm{mg} / \mathrm{Kg}$ and $4000 \mathrm{mg} / \mathrm{Kg})$ of experimental drug (ASG) were administered to them orally. The doses were divided into two fractions and were given within 12 hours. The animals were observed for mortality and clinical signs of toxicity at 1,2,3 and 4 hours and thereafter once a day for the next three days post ASG administration.

Chronic toxicity studies: A total of 80 rats (40 to group 4 and each group was consisted of 10 rats of each type. In practice group 1 was designated as Control group and rats were fed plain water; while each rat of group 2 was given a dose of Ashwagandharishta (0.625 $\mathrm{ml} / \mathrm{kg}$ of body weight). Similarly each rat of group 2 and group 3 was given a dose of Ashwagandharishta in an amount of $5.0 \mathrm{ml} / \mathrm{kg}$ of body weight and $40.0 \mathrm{ml} / \mathrm{kg}$ of body 
weight respectively. Following treatments the rats were observed for 51 days to know the effects of Ashwagandharishta on kidney functions considering 3 parameters such as serum urea, creatinine and uric acid.

Collection of Blood samples and preparation of serum: At the end of treatment period of 51 days, blood samples were collected from post vena cava of the rats (anaesthetizing with Ketamine (dose was $500 \mathrm{mg} / \mathrm{Kg}$ body weight) after 18 hour fasts. As soon as blood samples were collected it was centrifuged at a rpm of 4,000 for 10 minutes using a Bench top centrifuge (MSE Minor, England). Serum was collected and was stored in a refrigerator until further analyses. Period of analyses was 12 hours.

Biochemical studies: Serum samples were analyzed for Serum Urea, Serum Creatinine and Serum Uric acid using spectrophotometer (Vitros-250, Johnson \& Johnson) Random Access Multibatch Chemistry Analyzer (USA).

Statistical analysis: For interpretation of results, data statistically analyzed using SPSS program (version 16, IBM software Inc, USA).

\section{RESULTS AND DISCUSSION}

Acute toxicity study: The high dose of Ashwagandharishta (4000 mg/kg body weight) produced no death in the experimental animals. So, it was clear that the LD50 of ASG was greater than a dose of $4000 \mathrm{mg} / \mathrm{kg}$ body weight, which may suggest that a single dose of ASG administered orally could be safely used.

\section{Chronic toxicity study}

Effect of ASG on Serum Urea level of male \& female rat: When the male rats were treated with ASG, serum urea level was not changed significantly at any dose level. On the other hand, in case of female rat, all the doses of ASG showed statistically significant increase in serum Urea level at low dose (17.18 \% increases) and medium dose (14.85\% increase). At a high dose level, change in the Urea level was very high and increment was $24.16 \%$ (Table 2).

Table 2. The effect of ASG on the serum Urea level of male and female Albino rats after $\mathbf{5 1}$ days of treatment

\begin{tabular}{l|cc|c|c}
\hline \multirow{2}{*}{ Group and dose } & \multicolumn{4}{|c}{ Serum Urea (mg/dL) } \\
\cline { 2 - 5 } & \multicolumn{2}{|c}{ Male Rat } & \multicolumn{2}{c}{ Female Rat } \\
\cline { 2 - 5 } & Mean \pm SEM & $\%$ of Change & Mean \pm SEM & $\%$ of Change \\
\hline $\begin{array}{l}\text { Control group } \\
\text { ASG }(0.625 \mathrm{ml} / \mathrm{kg} \text { of } \\
\text { body weight })\end{array}$ & $29.93 \pm 1.34$ & - & $36.97 \pm 1.29$ & \\
$\begin{array}{l}\text { ASG }(5.0 \mathrm{ml} / \mathrm{kg} \text { of } \\
\text { body weight })\end{array}$ & $39.00 \pm 4.89$ & $\uparrow 7.58 \%$ & $43.32 \pm 2.04 * *$ & $\uparrow 17.18 \%$ \\
$\begin{array}{l}\text { ASG }(40.0 \mathrm{ml} / \mathrm{kg} \text { of } \\
\text { body weight) }\end{array}$ & $39.35 \pm 1.37$ & $\uparrow 30.32 \%$ & $42.46 \pm 1.39 *$ & $\uparrow 14.85 \%$ \\
\hline
\end{tabular}

Values are presented as mean \pm SEM $(n=10)$. One-way ANOVA followed by Dunnett's multiple comparison was performed to analyze the data set. ${ }^{*} p<0.05$, ${ }^{*} \mathrm{p}<0.01$ and ${ }^{*} \mathrm{p}<0.001$ was considered statistically significant. *(asterisk) marks represents statistically significant. Values are self explanatory. $\uparrow:$ increase, $\downarrow$ : decrease. 
Effect of ASG on Serum Creatinine of male \& female rat: All the doses of ASG showed no statistically significant change in serum Creatinine level of both male and female rat. But only the medium dose level for the male rat result showed a statistically significant increase $(67.98 \%)$ of serum Creatinine (Table 3$)$.

Table 3. The effect of ASG on the serum Creatinine level of male and female Albino rats after 51 days of treatment

\begin{tabular}{l|c|c|c|c}
\hline \multirow{2}{*}{ Group } & \multicolumn{3}{|c}{ Serum Creatinine $(\boldsymbol{\mu m o l} / \mathbf{L})$} \\
\cline { 2 - 5 } & \multicolumn{2}{|c}{ Male Rat } & \multicolumn{2}{c}{ Female Rat } \\
\cline { 2 - 5 } & Mean \pm SEM & $\%$ of Change & Mean \pm SEM & $\%$ of Change \\
\hline Control group & $0.38 \pm 0.01$ & - & $0.48 \pm 0.01$ & \\
ASG $(0.625 \mathrm{ml} / \mathrm{kg}$ of & $0.42 \pm 0.02$ & $\uparrow 11.02 \%$ & $0.53 \pm 0.03$ & $\uparrow 8.82 \%$ \\
$\begin{array}{l}\text { body weight }) \\
\begin{array}{l}\text { ASG }(5.0 \mathrm{ml} / \mathrm{kg} \text { of } \\
\text { body weight })\end{array}\end{array}$ & $0.64 \pm 0.11 *$ & $\uparrow 67.97 \%$ & $0.52 \pm 0.02$ & $\uparrow 6.77 \%$ \\
$\begin{array}{l}\text { ASG (40.0 } \mathrm{ml} / \mathrm{kg} \text { of } \\
\text { body weight) }\end{array}$ & $0.42 \pm 0.01$ & $\uparrow 11.02 \%$ & $0.51 \pm 0.01$ & $\uparrow 6.16 \%$ \\
\hline
\end{tabular}

Values are presented as mean \pm SEM $(n=10)$. One-way ANOVA followed by Dunnett's multiple comparison was performed to analyze the data set. ${ }^{*} p<0.05$, ${ }^{*} \mathrm{p}<0.01$ and $* \mathrm{p}<0.001$ was considered statistically significant. *(asterisk) marks represents statistically significant. Values are self explanatory. $\uparrow:$ increase, $\downarrow$ : decrease.

Effect of ASG on Serum Uric acid level of male \& female rat: All the doses of ASG showed no statistically significant increase in serum Uric acid of both male and female rat (Table 4).

Table 4. The effect of ASG on the serum Uric acid level of male and female Albino rats after 51 days of treatment

\begin{tabular}{|c|c|c|c|c|}
\hline \multirow[t]{3}{*}{ Group } & \multicolumn{4}{|c|}{ Serum Uric acid (mg/dL) } \\
\hline & \multicolumn{2}{|c|}{ Male Rat } & \multicolumn{2}{|c|}{ Female Rat } \\
\hline & Mean \pm SEM & $\%$ of Change & Mean \pm SEM & $\%$ of Change \\
\hline Control group & $0.80 \pm 0.05$ & - & $0.75 \pm 0.03$ & \\
\hline $\begin{array}{l}\text { ASG }(0.625 \mathrm{ml} / \mathrm{kg} \text { of } \\
\text { body weight })\end{array}$ & $1.27 \pm 0.32$ & $\uparrow 58.75 \%$ & $0.76 \pm 0.04$ & $\uparrow 0.55 \%$ \\
\hline $\begin{array}{l}\text { ASG }(5.0 \mathrm{ml} / \mathrm{kg} \text { of } \\
\text { body weight })\end{array}$ & $1.66 \pm 0.30$ & $\uparrow 108.62 \%$ & $0.89 \pm 0.05$ & $\uparrow 18.07 \%$ \\
\hline $\begin{array}{l}\text { ASG }(40.0 \mathrm{ml} / \mathrm{kg} \text { of } \\
\text { body weight })\end{array}$ & $1.62 \pm 0.42$ & $\uparrow 103.00 \%$ & $0.82 \pm 0.06$ & $\uparrow 9.10 \%$ \\
\hline
\end{tabular}

Values are presented as mean \pm SEM $(n=10)$. One-way ANOVA followed by Dunnett's multiple comparison was performed to analyze the data set. ${ }^{*} p<0.05$, ${ }^{*} \mathrm{p}<0.01$ and ${ }^{*} \mathrm{p}<0.001$ was considered statistically significant. *(asterisk) marks represents statistically significant. Values are self explanatory. $\uparrow:$ increase, $\downarrow$ : decrease.

In this present study, Ashwagandharishta treated male and female rats showed a trend of increment (although it was not statistically significant) in the three parameters i.e., serum urea, creatinine and uric acid than their corresponding control group. But a statistically significant increase was observed in serum urea in all three doses of Ashwagandharishta 
treated female rats (low: $\uparrow 17.18 \% *$, medium: $14.85 \%{ }^{*}$ and high: $\uparrow 24.15 \%,{ }^{*}$. For the serum creatinine level, a statistically significant increase was observed only for the medium dose male rat $(\uparrow 67.979 \% *)$ than their corresponding control group. And no statistically significant increase was observed for the uric acid level. It is claimed that an increase concentrations of uric acid might cause crystal formations in the bony joints, which can lead to inflammation and pain, a common manifestation of gout in men. Similar is the case with uric acid. Uric acid can also form crystals and kidney stones that can damage the organ. Therefore, Ashwagandharishta may be contraindicated for patients with kidney disorders and before administering this formulation a kidney function test is thus required.

Despite many similarities in different results of humans and laboratory animals, there are significant differences that should be taken into account when designing, conducting, and interpreting animal studies. Relevant pharmaco-toxicological properties of new chemical entities have to be extensively studied in laboratory animals before human administration (Casal \& Haskins, 2005; Kushwaha et al., 2012).

Animal models are commonly used in the preclinical development of new drugs to predict the metabolic behaviour of new compounds in human. It is however important to realize that humans differ from animals with regard to isoform composition, expression and catalytic activities of drug metabolizing enzymes (Martignoni et al., 2006). Therefore, this study may be helpful for drug researchers for extrapolating the results to human.

The present study was limited to just 51 days period on healthy male and female rats. It carries a scope for further evaluation of Ashwagandharishta preparation and also in long term randomized placebo controlled trial to establish its clinical use. Further studies are also required to assess whether the drug can improve other physical parameters or not.

Ethical approval: The present study was approved by the Biosafety, Biosecurity and Ethical Committee of Faculty of Biological Sciences, Jahangirnagar University, Savar, Dhaka-1342, Bangladesh.

\section{REFERENCES}

Anonymous. 1992. Bangladesh National Formulary of Ayurvedic Medicine (Approved by the Government of Bangladesh vide Ministry of Health and Family Welfare Memo No. Health-1/Unani-2/89 / (Part - 1) Dhaka, Bangladesh, 1992, Pp: 13-17.

Casal, M. and Haskins, M. 2005. Large animal models and gene therapy.Article-Literature Review in European Journal of Human Genetics 14(3): 266-72.

Edwards, N.L. 2016. Crystal deposition diseases. In: Goldman L, Schafer AI, eds. Goldman-Cecil Medicine. 25th ed. Philadelphia, PA: Elsevier Saunders; chap 273.

Kushwaha, R. and Karanjekar, S. 2011. Standardization of Ashwagandharishta formulation by TLC Method. International Journal of ChemTech Research. 3(3): 1033-1036.

Kushwaha, S., Betsy, A. and Chawla, P. 2012. Effect of Ashwagandha (Withania somnifera) Root Powder Supplementation in Treatment of Hypertension. Ethno Med, 6(2): 111-115. 
OECD, 2000. Guideline (425) for the testing of chemicals. Guidance document on acute oral toxicity, Environmental Health and Safety Monograph Series on Testing and Assessment. 1-27.

Margolis, S. 2015. Medical Editor, The Johns Hopkins Consumer Guide to Medical Tests, Updated by Remedy Health Media, The Editorial Staff at Healthcommunities.com, Published: 25 Jan 2012, Last Modified: 16 Mar 2015.

Martignoni, M., Geny, M.M. Groothuis, Ruben de, Kanter, 2006. Species and strain differences in drug metabolism in liver and intestine. University Centre for Pharmacy, Dept. Pharmacokinetics \& Drug Delivery, University of Groningen Ant. Deusinglaan 1, 9713 AV, Groningen, the Netherlands. page: 9

Sandhu, J. S., Shah, B., Shenoy, S., Chauhan, S., Lavekar, G. S. and Padhi, M. M., 2010. Internat. J. Ayur. Res. 1(3), 144-149.

Sharfuddin, A.A., Weisbord, S.D., Palevsky, P.M. and Molitoris, B.A. 2016. Acute kidney injury. In: Skorecki K, Chertow GM, Marsden PA, Taal MW, Yu ASL, eds. Brenner and Rector's The Kidney. 10th ed. Philadelphia, PA: Elsevier; chap 31.

Tanna, I. R., Aghera, H. B., Ashok, B. K. and Chandola, H. M. 2012. Pharma. Res. 33(1), 114118. 